\title{
Characteristics of EMG Responses to Imposed Limb Displacement in Patients with Vascular Hemiplegia
}

\author{
M.C. Verrier, W.G. Tatton and R.D.G. Blair
}

\begin{abstract}
The segmented EMG activity in flexor carpi radialis to imposed wrist movements was studied in 18 hemiplegic subjects with vascular lesions of the sensorimotor cortex or internal capsule and compared to that in age-matched normal subjects. The segmented EMG activity in the stretched muscle was normalized against the maximum $\mathrm{M}$ response elicited by electrical stimulation of its peripheral nerve in hemiplegic and normal subjects. This $M$ response was used to estimate the maximal activity of the motoneuron pool. Twelve of the hemiplegic patients showed a stereotyped abnormal segmentation pattern of the EMG activity characterized by: an increased MI segment of prolonged duration with both an increased sensitivity to low initial velocities of displacement and an increased slope of the input-output relationship for the range of velocities tested; absent or diminished activity during the interval of the normal M2-3 segment; and a late component not evident in normal subjects. The increased magnitude of the EMG activity during the $\mathrm{Ml}$ interval, markedly exceeded the normal range of control values. A method to demonstrate the response distribution of the interrelationship of the magnitude of the MI segment using two variables (background EMG activity and initial velocity) for individual responses rather than average responses is presented. The results of the study indicate that: the increased excitability, reflected in the enhanced $\mathrm{EMG}$ over the $\mathrm{M} 1$ segment does not result from increased levels of resting alpha motoneuron activity and may result from disruption of polysynaptic internuncial influences on alpha motoneurons; the absent or diminished activity over the interval of the normal M2-3 segment may partially result from the interruption of a transcortical reflex by the vascular lesions.
\end{abstract}

RÉSUMÉ: Nous avons étudié les réponses EMG au déplacement d'un membre chez 18 patients hémiplégiques avec lésions du cortex sensorimoteur, de la capsule interne, ou chez des témoins normaux du même âge. L'activité segmentaire EMG du muscle étendu fut comparée à la réponse maximum $\mathbf{M}$ élucidée par la stimulation électrique du nerf périphérique dans les témoins hémiplégiques et normaux. Cette réponse s'employa pour estimer l'activité maximale de la population de motoneurones. Douze patients hémiplégiques montrèrent une segmentation anormale pareille de l'activité EMG caractérisée par: un segment augmenté M1 de durée prolonguée avec une sensibilité augmentée à des vélocités initiales de displacement à des niveaux de base bas et avec une pente augmentée de la realation de l'input et de l'output; l'activité absente ou diminuée pendant l'intervalle du segment normal M2-3; et un composant pas évident chez les témoins normaux. La magnitude augmentée de l'activité EMG pendant l'intervalle MI excéda beaucoup les variations normales. Une méthode se présente pour montrer la distribution des réponses des inter-relations de la magnitude du segment MI utilisant deux variables (l'activité EMG d'arrière-plan et la velocité initiale) pour les réponses individuelles plutôt que les réponses moyennées. Cette étude indique que l'augmentation d'excitabilité ne provient pas d'une excitabilité accrue polysynaptique inter-neuronale des motoneurones alpha, et que l'activité absente ou diminuée pendant l'intervalle du segment normal M2-3 est le résultat partiel de l'interruption d'un reflexe transcortical par la lesion vasculaire.

Can. J. Neurol. Sci. 1984; 11:288-296

Muscle tone is assessed clinically by estimating the resistance of a joint-muscle system to imposed displacement. In an attempt to understand the peripheral and central neural mechanisms of muscle tone, electromyographic (EMG) responses to imposed joint movements have been extensively investigated. The EMG responses in muscles stretched by displacements of the human wrist are segmented into a short latency component (M1) and one or more long latency components (M2-3) (see Tatton et al., 1983 for a discussion of the temporal characteristics of the segmental responses at different joints and in different species). The magnitude of the $M 1$ and M2-3 segments is simultaneously dependent on imposed movement parameters such as the initial

From the Playfair Neuroscience Unit, Department of Rehabilitation Medicine, University of Toronto and Jackman Neuroscience Laboratory, West Park Hospital, Toronto, Canada

Received November 10, 1983. Accepted for publication March 5. 1984.

Reprint requests to: M.C. Verrier, Playfair Neuroscience Unit, Toronto Western Hospital, 399 Bathurst Street, Toronto, Ontario M5T 2S8 
velocity of the imposed displacement and the level of preexisting EMG activity in the stretched muscle (Bedingham and Tatton, 1984).

Characteristic abnormalities in the segmented $\mathrm{EMG}$ responses have been demonstrated quantitatively for several different neurological disorders (see Tatton et al., 1984 for an overview). Lesions involving the pre- and post-central cortex, internal capsule, or doral columns in humans result in diminuation or abolition of activity over an interval corresponding to the normal M2-3 segments for different joint-muscle systems (Lee and Tatton, 1975 and 1978; Marsden et al., 1977a, b; Chan et al., 1979).

Chan et al. (1979) were able to record long latency responses in the upper limb but not in the lower limb in patients with spastic paraplegia due to thoracic spinal cord lesions. This finding was interpreted as providing evidence that supraspinal facilitation is needed to elicit long latency responses. Subsequently, Lee et al. (1983) studied the upper limb of a group of non-homogenous patients with cerebral lesions and reported three distinct segmental activity patterns in different groups of patients with an accentuation of activity over the M1 segment in all cases.

The present study was undertaken to extend these findings by investigating the characteristics of the segmented responses in the wrist musculature of patients with vascular lesions involving the sensorimotor cortex or internal capsule. The advantages of using the wrist muscles to study the segmental activity in hemiplegic subjects are twofold: 1) both short and long latency segments can be predictably recorded in normal subjects; and 2) "response planes" simultaneously demonstrating the interrelationship of one or more displacement parameters and the pre-existing EMG activity to the magnitude of the segmental EMG responses can be compared to those for normal control populations (Bedingham and Tatton, 1984).

The results of the study show that 12 of the 18 hemiplegic subjects had increased short latency activity over the time interval of the normal Ml segment together with absent or decreased activity over the interval of the normal M2-3 segment despite low levels of spontaneous background EMG activity in the stretched muscles.

\section{Methods}

Thirty-two patients with unilateral infarcts of either the sensorimotor cortex or internal capsule were investigated. Eighteen of these patients ( $\bar{x}$ age $68.5 \pm 8.8$ years) met the specified clinical criteria. The duration between the infarct and the testing varied for the individual patients $(\bar{x} 117$ days; $1-60$ days $(n=9), 60-100$ days $(n=4), 145-430$ days $(n=5))$. On clinical examination the patients had increased tendon jerks and extensor plantar responses $(n=18)$ hypertonic wrist flexors $(n=12)$ and hypotonic wrist flexors $(n=6)$. To ensure that comparison was made with appropriate normative data, 17 age-matched ( $\bar{x}$ age $64.9 \pm 4.7$ years) normal subjects served as controls. This was done rather than measuring data from the contralateral limb to avoid interpretive problems due to clinically undetected bilateral abnormalities resulting from multiple vascular lesions.

The subjects sat in a chair designed to prevent extraneous voluntary activity of the axial and proximal upper limb muscles from influencing the EMG activity of the muscles tested. The arm was supported with the elbow in $90^{\circ}$ flexion and the wrist was in the subject's natural resting position. Each subject's hand was firmly taped to a handle coupled to a torque motor. Five different step loads, in either the flexion or extension direction, were presented to the subject. The size of step load, direction, duration and the delay between displacements were randomly calculated by computer. Differentially amplified surface EMG was measured from flexor carpi radialis (FCR) and extensor digitorum communis (EDC) and recorded simultaneously with position and tension.

Averages of the EMG activity and the movement displacements were constructed for 12 to 30 individual presentations. The experimental procedure and data analysis were similar to that described in detail in Bedingham and Tatton (1984) with the following exceptions: 1) Hemiplegic subjects, due to the varying degree of paresis, cannot perform a maximum voluntary contraction. Therefore, normalization of the response activity against the maximum voluntary activity (MVA) was an inappropriate measure. Instead of using \% MVA the response activity and background EMG activity were normalized against a maximum $\mathrm{M}$ response $(\mathrm{Mr}$ ) elicited by direct electrical stimulation (single $1.0 \mathrm{msec}$ pulse) to the motor nerve of the appropriate muscle (see Lenz et al., 1983b for an example of the use of this measure). 2) Hemiplegic patients had some limitation in wrist movement and usually rested in some degree of flexion. Therefore, the angular displacements were limited to the patient's passive range of movement as compared to the normal subjects whose displacement range of movement was $50^{\circ}$ flexion or extension. 3) The hemiplegic subjects could not maintain a prolonged muscle contraction against a maintained load due to the paresis. Therefore responses were out of necessity recorded at their spontaneously occurring background EMG levels. For the normal subjects a continuous preload was applied to only those subjects where EMG responses could not be elicited without some increase in the tonic background activity (the remaining normal subjects were recorded at spontaneous EMG levels). 4) The magnitude of the $M I$ response for the hemiplegic subjects was measured over the mean duration of the M1 segment ( $23 \mathrm{msec}$ ) for the age-matched controls (see results section for details).

Three-dimensional "response planes" showing the relationship of the initial velocity, pre-existing background EMG activity and the magnitude of the $M 1$ responses, created for a population of young normal subjects or with altering background for one subject, have been described in the companion paper (Bedingham and Tatton, 1984). These "response planes" can be constructed for a population from averaged data of different individual subjects who show a range of different background EMG levels. To establish this interrelationship is important because background EMG levels in normal subjects have a major effect on MI magnitude together with related movement parameters such as initial velocity (see Bedingham and Tatton, 1984, for discussion).

In hemiplegia, the background EMG levels were consistently low making comparison of the "response planes" with normal subjects difficult. Furthermore, hemiplegic subjects cannot adequately maintain muscle contraction against prolonged preloads for longer than 10 to 20 minutes. Therefore, a new approach was required to demonstrate the relationship of this interdependence and to compare normals and hemiplegics. In those hemiplegic patients who were not completely paralyzed, the preload and step load magnitudes for individual trials were randomly changed. Five different preload and 3 different step 
load magnitudes were applied to create a three-dimensional response "distribution" (see figure 5 in the results section). The distributions were constructed by binning the data according to two variables (background EMG levels and initial input velocities). The magnitude of the $\mathrm{Ml}$ interval was normalized against the $\mathrm{Mr}$ and the mean $\mathrm{Ml} / \mathrm{Mr} \%$ for each background level at a given initial input velocity was plotted. This approach allowed us to look at a range of EMG responses for a given individual hemiplegic subject in comparison to a normal subject.

In addition, in one subject who had adequate voluntary muscle strength in the forearm extensors to maintain a neutral wrist position against a $0.6 \mathrm{Nm}$ preload, we displaced the wrist into extension to examine the effects of reciprocally acting voluntary activation (EDC) on FCR responses.

\section{RESULTS}

All control subjects showed $M 1$ segments with a latency $(\bar{x}$ $35.4 \mathrm{msec} \pm 4.9$ ) which appears consistent with the values reported for younger normals given the low spontaneous background levels. That is, the increase in M1 latency of 4 to 5 msec in the elderly normal subjects is similar to that found in young normal subjects (Bedingham and Tatton, 1984) at low background EMG levels. The mean background levels in the control and hemiplegic subjects in this study $(2 \% \mathrm{Mr}$ and $3 \% \mathrm{Mr}$ respectively) would correspond to levels that are lower than $4 \%$ to 5\% MVA reported previously by Bedingham and Tatton (1984) (in preparation). Therefore, if the older subjects had been consistently contracting against a maintained preload producing higher background EMG levels the latency of the M1 segment would be expected to be comparable.

Figure IA (lower trace) illustrates $M 1$ and M2-3 segmental activity for the FCR in a representative normal subject (age 57 years) for 5 different step load magnitudes. The individual subject, selected in this case because of relatively high background EMG levels (6.0\% Mr to 6.6\% Mr), shows $\mathrm{Ml}$ and M2-3 segments with constant latency and $\mathrm{MI}$ magnitudes that increased from $4.2 \% \mathrm{Mr}$ to $10.7 \% \mathrm{Mr}$ for the increasing initial displacement velocities. The values are similar to those reported for younger normal subjects (Bedingham and Tatton, 1984). The dotted lines in figure 1 mark the mean latency $(35 \mathrm{msec})$ and duration for the Ml (23 msec) and the mean duration for the M2-3 (52 $\mathrm{msec}$ ) for the population of age-matched normal subjects.

Figure $1 \mathrm{~B}$ shows the abnormal segmented response found for 12 of the 18 hemiplegic subjects. Onset latencies ( $\bar{x} 36.5 \mathrm{msec} \pm$ 5.0 ) in the hemiplegic subjects for the $M 1$ were not significantly different from normals. Given the relatively lower background levels in this patient $(2.3 \% \mathrm{Mr}$ to $2.6 \% \mathrm{Mr})$ the initial EMG segment is increased in magnitude $(19.1 \% \mathrm{Mr}$ to $33.6 \% \mathrm{Mr})$ and prolonged. The initial segment is followed by a period of reduced
NORMAL SUBJECT

HEMIPLEGIC SUBJECT
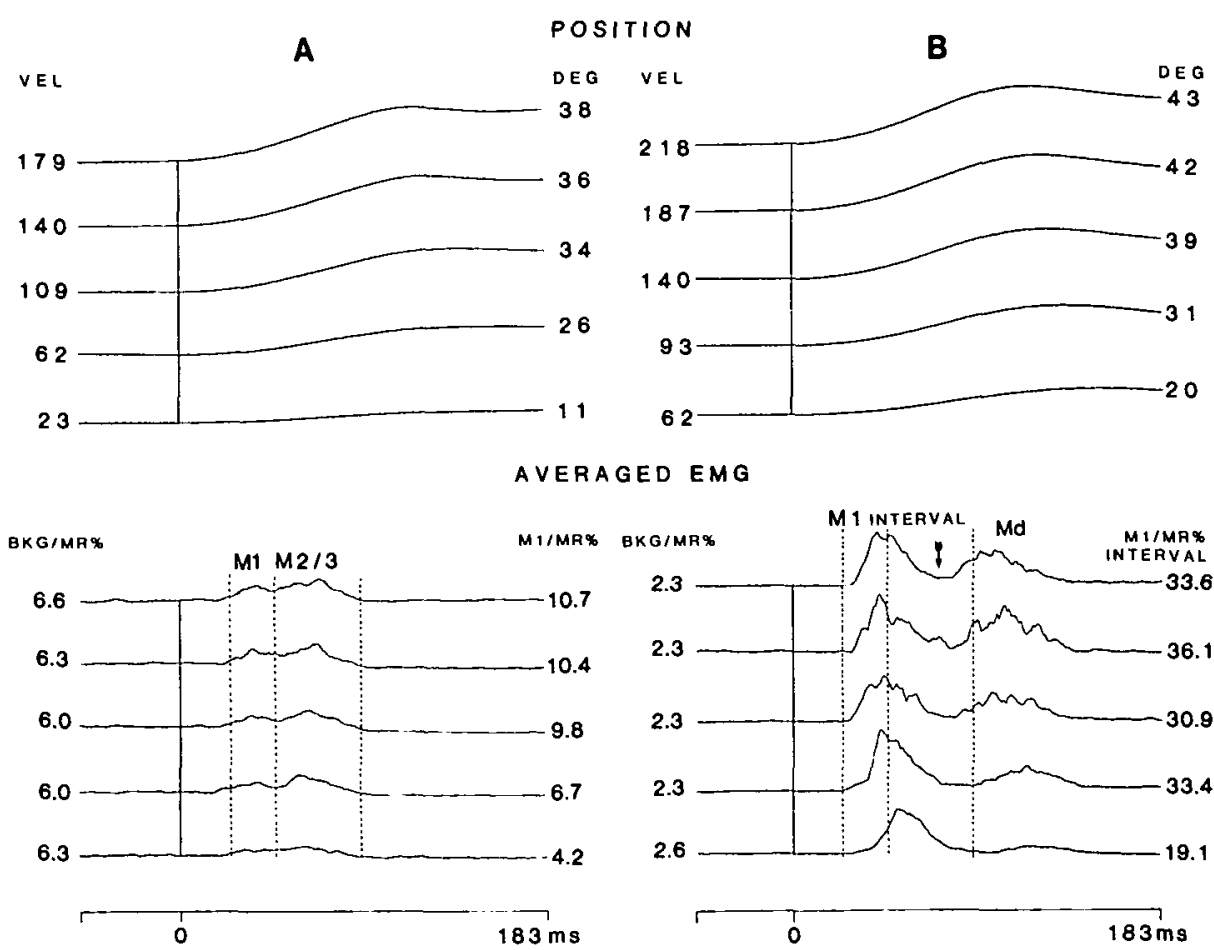

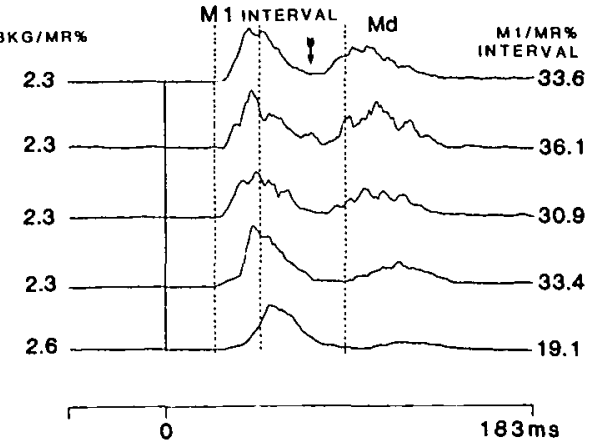

Figure 1 - Example of the averaged position traces and EMG segmentation for a normal subject $(A)$ and a hemiplegic subject $(B)$ to a series of five different step load magnitudes. The top traces illustrate the five significantly different displacements with the initial velocity (left) and degree of inovement displacement (right). The lower traces illustrate the averaged EMG activity from the stretched FCR muscle with the resting background levels and $M I I M r \%$ magnitudes for the five different displacements. The dotted lines indicate the mean latency and duration for the age-matched normal subjects for the MI (x) $35 \mathrm{msec}, \bar{x} 23 \mathrm{msec}$ ) and M2.3 (.. $58 \mathrm{msec}, \dot{x} 52 \mathrm{msec})$. The data for the normal subject is comparable to figure 3 (Bedingham and Tatton. 1984) given that the data is normalized against the Mr. B illustrates the enhanced MI magnitude in the hemiplegic subject $(19-33 \% \mathrm{Mr})$. The arrow indicates the inhibition over the normal M2.3 interval. There is a delaved component labelled Md of unknown origin. 
activity (indicated by the arrow) over the normal M2-3 interval followed by a further burst of activity (labelled $M d$ ) not found in normals. As shown in this figure the latency of the Md increased with the decreasing initial velocities of displacement (particularly for the two smallest step load magnitudes). This was in contrast to the normal M2-3 segment that maintained a constant latency as illustrated in figure $1 \mathrm{~A}$ despite decreasing initial velocities.

The duration of the initial segment of the EMG responses in the hemiplegic subjects compared to the normals, as illustrated in figure $1 \mathrm{~B}$, was prolonged (normal subject in figure $1 \mathrm{~A} 23$ $\mathrm{msec}$, hemiplegic subject in figure 1B $46 \mathrm{msec}$ to $60 \mathrm{msec}$ ). Since the duration of the Ml segment in hemiplegics was markedly prolonged beyond the interval for the constant duration $\mathrm{MI}$ in normals the magnitude would not be directly comparable if the mean activity over the total segment were measured. Therefore, the first $23 \mathrm{msec}(\overline{\mathrm{x}} \mathrm{M})$ duration for the normal population) was used to measure $M 1$ segmental activity in the hemiplegic subjects. This initial interval was termed the MI "interval" in the hemiplegic patients.

The responses to 20 individual trials for the highest step load in a typical control subject and hemiplegic patient (figure 2, upper panel left and right) illustrate how consistent the latencies and magnitude of the initial EMG segments in a hemiplegic subject are in comparison to the Ml segments in a normal subject. In the normal subject there is some variability in the MI segments which depends on the level of background EMG activity (note the increased magnitudes in the individual trials with variations in background levels prior to the MI segment). In marked contrast, the hemiplegic subject shows a $\mathrm{M} 1$ interval with constant latency and a consistent rapid rise in the EMG activity for the initial segment even at low resting background EMG levels. These individual trials show how stereotyped, from presentation to presentation, the MI segmental activity is in hemiplegia. In the lower panel, data from twenty individual trials for these two subjects are presented. Background levels (control $\dot{\mathrm{x}} 4.3 \% \mathrm{Mr} \pm 1.5$, hemiplegic $\dot{\mathrm{x}} 2.7 \% \mathrm{Mr} \pm .53$ ) and latencies for the $M 1$ (control $\bar{x} 36.6 \mathrm{msec} \pm 4.4$, hemiplegic $\bar{x}$ $39.6 \mathrm{msec} \pm 3.2$ ) are relatively constant. There is a striking increase in the $\mathrm{Ml}$ interval magnitude for the hemiplegic subject $(\overline{\mathrm{x}} 54.4 \% \mathrm{Mr} \pm 11.2)$ in comparison to the $\mathrm{Ml}(\overline{\mathrm{x}} 8.4 \% \mathrm{Mr} \pm 2.9)$ for the normal subject.

In order to examine the sensitivity to the movement displacement (in this case the magnitude of the $M l$ segmental activity at the lowest velocity tested) and the slope of the MI magnitude over the five different initial velocities tested, the magnitude of the normal $\mathrm{Ml}$ and activity over the $\mathrm{Ml}$ interval in hemiplegia was plotted against the initial displacement velocity (figures 3 and 4). Figure 3 is an input-output plot relating the initial movement velocity (abcissa) to the MI magnitude (ordinate) and shows the monotonic relationship of these variables for ten representative normal subjects. The $\mathrm{M} 1 \mathrm{magnitude}$ was consistently below $14 \% \mathrm{Mr}$ (the level represented by the dotted line) in normal subjects for initial input velocities up to $300 \% \mathrm{sec}$ and background activity ranging between $1.3 \% \mathrm{Mr}$ and $5.6 \% \mathrm{Mr}$ (shown at the end of each trace).

Figure 4 shows a plot of the same variables for 18 hemiplegic subjects. The spontaneous background EMG levels are lower in the hemiplegic subjects $(\overline{\mathrm{x}} 2.3 \% \mathrm{Mr} \pm 1.2)$ in comparison to the normal subjects $\bar{x} 3.0 \% \mathrm{Mr} \pm 1.5$ ) indicating that background excitability of the alpha motoneurons is not likely to account directly for the increased magnitude of the $\mathrm{Ml}$ interval in the hemiplegic patients. The group of hemiplegics who had the typical abnormal segmented response pattern similar to that illustrated in figure $1 \mathrm{~B}$ are marked with an asterisk. Interestingly. this group shows both an increased sensitivity to low initial velocities of displacement (initial $M 1$ interval magnitudes except in one case are greater than $10 \% \mathrm{Mr}$ at the lowest velocity tested) and an increased slope in the input-output plots for the

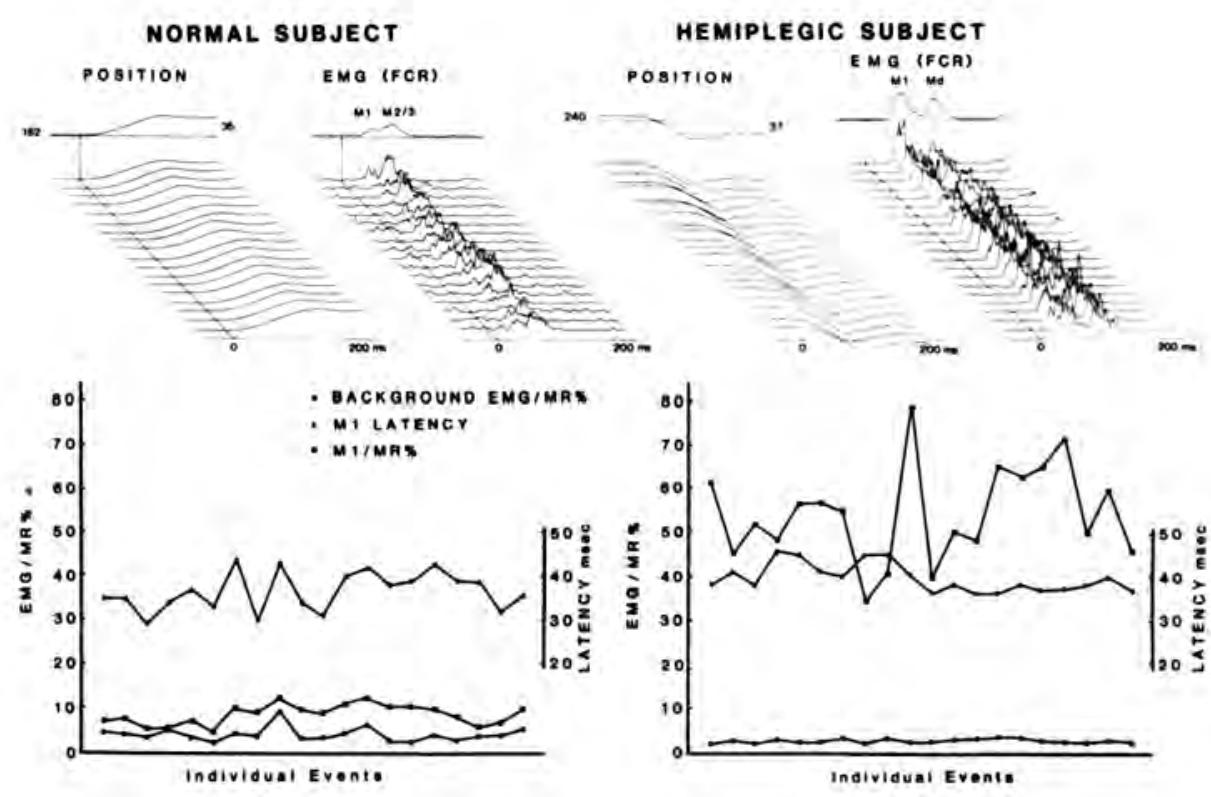

Figure 2 - Individual trials for the largest step load (top trace) demonstrate the consistency of the responses in a given individual. Data for individual trials in the hemiplegic subject (lower right trace) illustrate the increased $M I$ interval $(n=20)$ with low resting background levels. 
NORMAL SUBJECTS

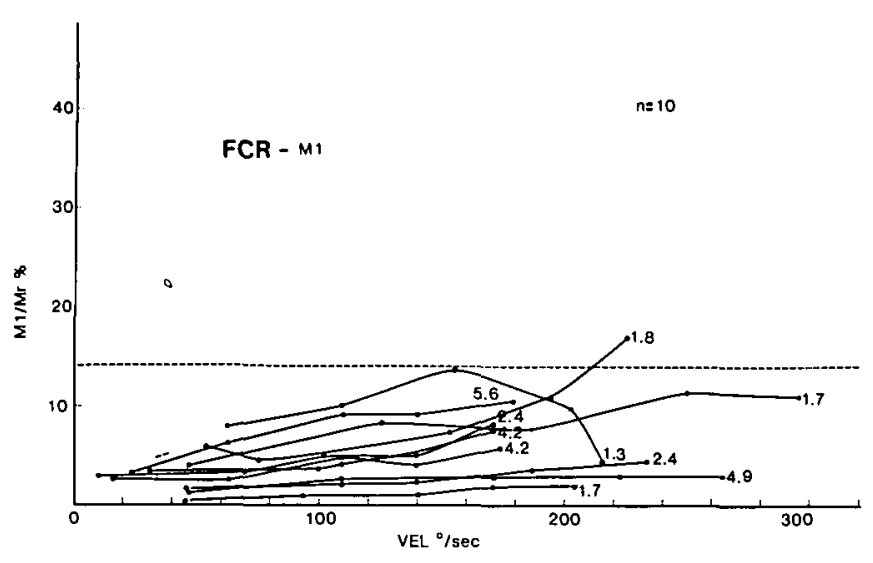

Figure 3 - Magnitude of the MI segment with respect to the increasing initial displacement velocity for 10 representative normal subjects. Each line represents a single individual tested with 5 different step load magnitudes. The numbers on the right are the resting background EMG levels. Note that the MI response magnitude in most cases does not exceed $14 \% \mathrm{Mr}$ even at velocities up to $300^{\circ} / \mathrm{sec}$.

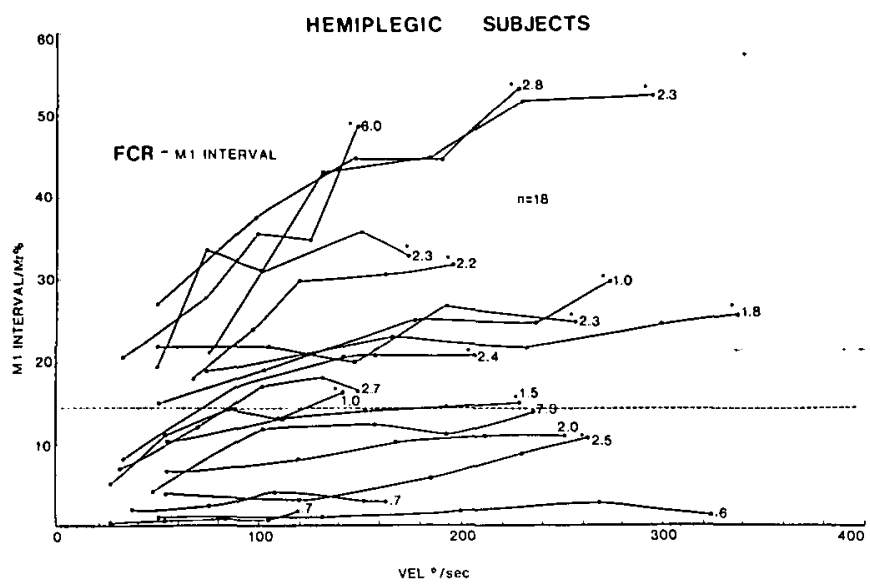

Figure 4 - Figure 3 is a similar plot to figure 2 for the hemiplegic subjects $(n=18)$ (note the difference in the scale). The subjects with an asterisk are those subjects who showed EMG activity similar to the example in figure I $B$. The increased sensitivity to movement displacement is demonstrated in those subjects who have a MI interval segment greater than $14 \% \mathrm{Mr}$ for initial velocities less than $100 \% \mathrm{sec}$. The increased slope of the responses demonstrates how the MI interval can increase up to $50 \% \mathrm{Mr}$ in some cases with velocities less than $300^{\circ} / \mathrm{sec}$.

initial velocities tested (note the three subjects who have $\mathrm{M} 1$ interval activity above $40 \%$ for the highest initial velocities tested). The slope of the input-output relationship is higher in these hemiplegic patients even when the background levels are low which is inconsistent with results in normal subjects. The dotted line at $14 \% \mathrm{Mr}$, included to aid comparison with the normal subjects plotted in figure 3, shows that in all but one case the magnitudes of the typical abnormal MI interval are consistently increased when compared to the $\mathrm{Ml}$ segments in the normal subjects.
Figure $5 \mathrm{~A}$ and $5 \mathrm{~B}$ illustrate a single trial response distribution for a normal subject and a hemiplegic subject for 5 different preload and 3 different step load magnitudes. Background levels up to $6 \% \mathrm{Mr}$ are plotted to the left and initial input velocities up to $400 \% \mathrm{sec}$ are plotted to the right. The response distribution is within the normal range of the $\mathrm{Ml}$ response plane (Bedingham and Tatton, 1984). Response planes show a distribution of averaged responses drawn from a population of subjects. The planes clearly portray the trend for the increase in the M1 magnitude with increasing initial velocities and background EMG activity but are not as exact as the response distributions drawn from individual trials subject to randomly occurring extraneous variables. Figure 5A shows that as the initial velocity increases there are small increases in the M1 magnitude. Similarily, but more evident in this distribution, as the background EMG level increases the $M 1$ magnitude increases. The mean MI magnitude for a given initial input velocity at a given background level is represented by the vertical columns. For purposes of comparison, the shaded columns present mean $\mathrm{MI}$ interval magnitudes of $2.5 \% \mathrm{Mr}$ (normal subject) and $43.3 \% \mathrm{Mr}$ (hemiplegic subject) for background EMG levels of $0.9 \% \mathrm{Mr}$ and initial velocities of $208 \% \mathrm{sec}$. Figure $5 \mathrm{~B}$ also illustrates how background EMG levels appear to have a less obvious influence on the magnitude of the MI interval in hemiplegia in comparison to normals due to the high sensitivity over the range of lower initial velocities.

In fact, increased $M 1$ interval activity could be elicited in FCR even when the reciprocal antagonistic extensor muscle was voluntarily contracting against a preload to maintain a neutral position. This would normally result in minimal FCR activity (figure 6). Figure 6 shows the effect of applying a $0.6 \mathrm{Nm}$ load to the antagonistic extensor muscles of the forearm and displacing the wrist into extension for a normal subject and a hemiplegic subject. For a comparable preload to be maintained the_hemiplegic subject (B) requires increased muscle activity from both muscles ( $26 \% \mathrm{Mr}$ EDC; $3 \% \mathrm{Mr} F C R$ ) in contrast to the normal subject (A) (4\% Mr EDC; 5\% Mr FCR). Note the increased MI interval activity of $39 \% \mathrm{Mr}$ for the hemiplegic subject in comparison to the normal where no MI for FCR can be evoked. It appears that the normal reciprocal inhibition from antagonists to agonist is markedly altered.

The remaining 6 subjects had EMG responses with variable EMG segmentation that did not correspond to the control subjects or other hemiplegic subjects. The magnitude of the MI interval in these subjects was not increased (figure 4).

\section{Discussion}

Previous studies have shown the characteristics of the EMG responses to wrist flexor displacement in a population of young normal subjects using the MVA for normalization of the EMG measures for intersubject comparison (Tatton and Bedingham, 1981; Bedingham and Tatton, 1984). Because of the paresis we have used $\mathrm{M}$ responses and established some baseline values for the $\mathrm{M} 1$ segment over a limited range of background activity levels as measured against the $\mathrm{Mr}$ in a group of elderly subjects (fixed latency, constant duration, and monotonic grading with initial displacement velocities in the range of $5-300 \%$ sec). Particularly, using the $\mathrm{M}$ response as an indirect measurement of maximal activity of the motoneuronal pool we were able to establish that the MI segment in most cases in normal subjects 
A

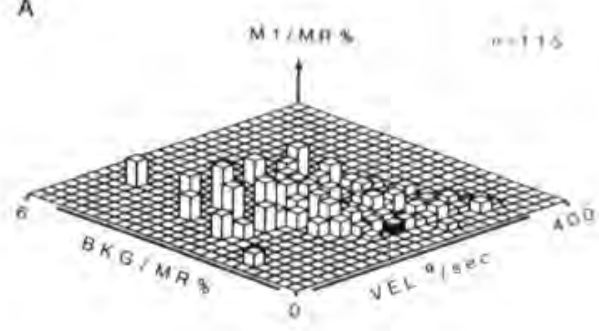

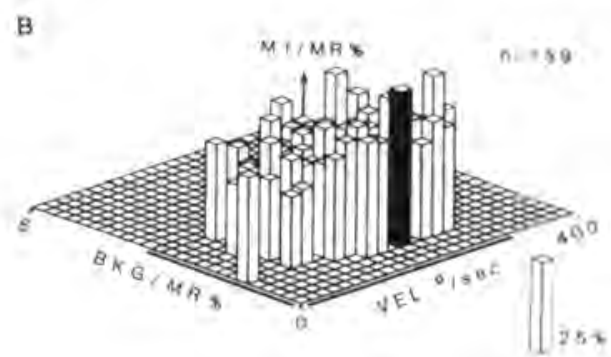

Figure 5 - Response "distribution" calculated for a normal subject by varying the background EMG activity and input displacemem velociry. The shaded columns indicate the difference in MI magnitude for a velocity of $208 \% \mathrm{sec}$ and background EMG level of $0.9 \% \mathrm{Mr}$. The response magnitude is $2.5 \% \mathrm{Mr}$ in the control subject and $43.3 \% \mathrm{Mr}$ in the hemiplegic subject.

NORMAL SUBJECT,

A

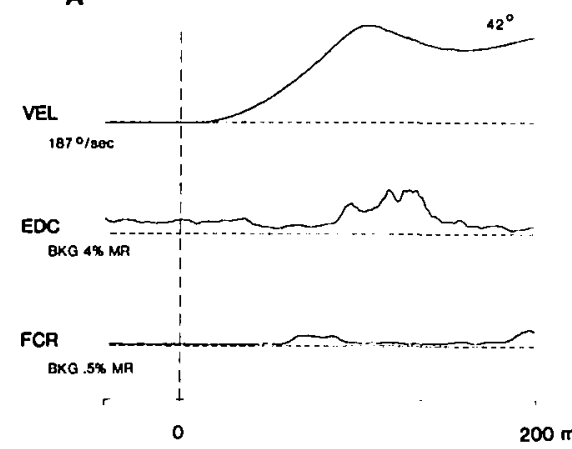

HEMIPLEGIC SUBJECT

B

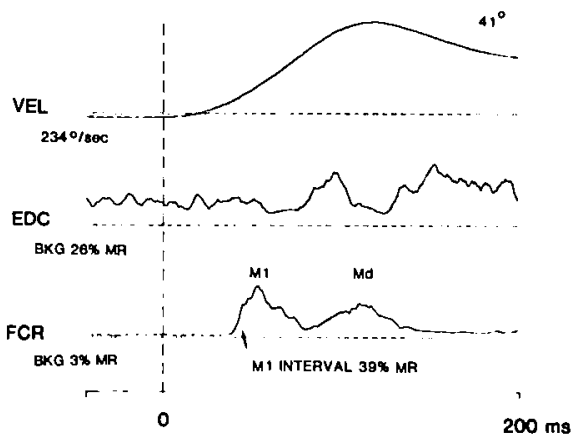

Figure 6 - The effect of decreasing background activity of the FCR $(0.5 \% \mathrm{Mr})$ by increasing the antagonist voluntary activity for EDC $(4.0 \% \mathrm{Mr})$ in a normal subject $(A)$. In the hemiplegic subject $(B)$ where EDC background activity is $26 \% \mathrm{Mr}$. the MI activity is still increased up $1039 \%$ of the FCR Mr.

was less than $14 \% \mathrm{Mr}$ in comparison to hemiplegics where $\mathrm{MI}$ activity over the same segmental interval was often three times the normal magnitude for a given initial velocity.

In most hemiplegics the displacements produced a stereotyped high magnitude $\mathrm{M} 1$ segment at low background levels for a variety of initial velocities. Although direct comparison between MVA and Mr cannot be made, the values would appear to fall outside the response volume for normal subjects measured using \% MVA (Bedingham and Tatton, 1984). We have found some intersubject variation in \% MVA and \% Mr ratios for FCR in normals (in preparation) but using the data from figures 3 and 4 the $\mathrm{M} 1$ interval response volume in hemiplegic subjects would be markedly different to the normal controls in this study for the limited range of background EMG levels recorded. Specifically, the Ml interval in the hemiplegic subjects showed the following characteristics: 1) consistent responses in a given subject; 2) constant latency implying that neural conduction time and central processing delays are similar to normals; 3 ) prolonged duration; 4) increased sensitivity to the movement displacement for the velocities tested; 5) increased slope in the input-output plots in some subjects;6) spontaneous background levels that were low; and 7) background activity that had only a marginal effect on the increased magnitude of the MI segmental activity in comparison to the initial velocity.

Background levels of EMG activity have a major effect on the $\mathrm{M} 1$ segment magnitude in young normal subjects (Bedingham and Tatton, 1984). A similar effect in an older normal subject is shown in figure 5A where increasing the background EMG level for individual trials influences the $\mathrm{M} 1$ magnitude often up to four times that at low levels of background EMG. In contrast, the effect of background EMG activity on the Ml interval magnitude in the hemiplegic subject (figure 5B) is less apparent . Similar findings for the short latency response in the lower extremity have been shown. Berardelli et al. (1983) have shown that the short latency response in the lower extremity of a group of patients with mixed upper motoneuron lesions producing spasticity is enhanced by voluntary contraction in those situations only where the short latency response was not already increased. It would appear therefore that in hemiplegia the $\mathrm{MI}$ is more sensitive to the initial velocity of the displacement than the background EMG levels. 
The increased activity over the MI interval could be a manifestation of one or more alterations in the normal segmental circuitry devoid of normal descending inputs, a fundamental deficit in hemiplegia. Firstly, the increased sensitivity to the low initial velocities seen in the hemiplegic subjects with M1 interval magnitudes greater than $10 \% \mathrm{Mr}$ at initial input velocities of less than $60 \% \mathrm{sec}$ could be attributed to increased fusimotor drive. Increased fusimotor drive was proposed originally by Granit (1955) as a possible factor in spasticity. However, increased muscle spindle sensitivity should be reflected in high la spindle afferent activity as assessed by microneurographic recordings if gamma drive is involved in spasticity. Hagbarth et al. (1973) could not record an increase in either static or dynamic sensitivity of muscle spindles in spasticity in two hemiplegic subjects. In contrast, Szumski et al. (1974) found increased sensitivity of spindle afferents during clonus or electrically induced muscle twitches in seven subjects with spasticity caused by various neurological conditions as compared to normals providing an indirect suggestion of increased gamma drive in spasticity.

Hemiplegic subjects characteristically show pleomorphic EMG abnormalities (for example only 12 of the 18 subjects in this study showed similar alterations in their responses). The relatively small number of subjects with different types of spasticity tested in the previous two studies could be similar to either the one third of the subjects that did not show the characteristic abnormal segmental pattern of the $\mathrm{M} 1$ response or to the two thirds of the subjects who had the abnormal segmental pattern or to neither group. Therefore, we cannot utilize the microneurographic studies to reach a firm conclusion about the role of gamma drive as the basis for increased activity during the $\mathrm{M} 1$ interval. However, it would be important to classify hemiplegic patients into two groups, those who have decreased sensitivity to the initial velocity of the displacement and those who do not. Microneurographic recordings from the median nerve in the former group could be used to assess increased gamma drive.

Secondly, the increased magnitude of the $\mathrm{Ml}$ interval in hemiplegic subjects could be accounted for by increased alpha motoneuron excitability. If the alpha motoneurons themselves were hyperexcitable it should be reflected in relatively high background EMG levels. A comparison of background levels with the normal subjects showed that this was not the case. In fact, increased activity over the $\mathrm{M} 1$ interval could be elicited in all hemiplegic subjects at relatively low background levels (see figure 4). Similar findings have been reported for the monkey forelimb where increased MI activity was apparent at low spontaneous background EMG levels following contralateral cortical lesions involving the forelimb portion of area 4 (Lenz et al., 1983b). Apparently alpha motoneurons are not necessarily hyperexcitable in hemiplegics.

In fact, previous evidence for increased alpha motoneuron excitability in hemiplegic man has been indirect. $H$ reflex studies designed to measure la monosynaptic reflexes as a measure of alpha motoneuron excitability have shown increased $\mathrm{H} / \mathrm{M}$ ratios (Zander-Olsen and Diamantopoulous, 1967; Somerville and Ashby, 1978). In addition, $H$ reflexes can be more easily obtained in the upper extremity of hemiplegics than normal subjects (Garcia-Mullen and Mayer, 1973). Taken together these two findings could be taken to suggest increased alpha motoneuron excitability. However, the conclusions were based on the assumption that the $\mathrm{H}$ reflex measures monosynaptic input to alpha motoneurons from la spindle afferents only. Recent work by Burke et al. $(1983,1984)$ has questioned the premise that $\mathrm{H}$ reflexes and Achilles tendon reflexes (ATR) are mediated by monosynaptic pathways. Specifically, they interpreted that the $10 \mathrm{msec}$ rise time of the excitatory postsynaptic potential from single motor units conditioned by tendon percussion during voluntary contraction was adequate for ogliosynaptic pathways to influence the reflex discharge. Accepting Burke's findings, direct evidence of an isolated increase in the excitability of alpha motoneurons in spasticity cannot be obtained using ATR and $\mathrm{H}$ reflex methodologies. It is more likely that the central excitability is an alteration in polysynaptic inhibitory influences.

Extrapolating from Burke's findings with the ATR, the M1 segment also does not equate to a monosynaptic reflex. The Ml response has a comparable duration to a tendon jerk in the wrist flexors (Lee and Tatton, 1982) and the afferent input could be generated by cutaneous, muscle and/or joint receptors. Interneurons devoid of supraspinal influences could amplify these sensory inputs resulting in increases in $\mathrm{M} 1$ segmental activity in hemiplegia. This would be evidenced by the increased slope of the input-output relation for the $\mathrm{Ml}$ response that occurred in hemiplegic-subjects with background levels as low as $1.0 \% \mathrm{Mr}$ in contrast to young normal subjects (Bedingham and Tatton, 1984) and the older normal subjects in this study. Notably the input-output plots of the $\mathrm{M} 1$ interval for some hemiplegic subjects had not maximized even at velocities up to $200 \% \mathrm{sec}$.

The inability to modulate the $\mathrm{Ml}$ even with antagonistic extensor activity adds the possibility of a further abnormality, that is, the disruption of reciprocal inhibitory internuncial influences. $\mathrm{H}$ reflex conditioning studies using antagonistic muscles in the lower extremity of hemiplegics have been taken to suggest that reciprocal inhibition from flexors to extensors is altered in hemiplegia (see Tanaka, 1983 for a discussion). Our findings could be taken to support a similar abnormality for the flexor muscles of the upper extremity, but are not sufficient to reach a firm conclusion regarding this matter.

Alternatively it could be argued that in hemiplegics the M1 interval/ $\mathrm{Mr}$ ratio could be artificially high if the $\mathrm{Mr}$ is decreased. Decreased $\mathrm{Mr}$ amplitude and motor unit counts have been reported previously in the extensor digitorum brevis in hemiplegia (McComas et al., 1973). Motor unit counts were related to the duration of the lesion with relatively normal counts up to 2 months, decreasing to $50 \%$ between 2 and 6 months while the $\mathrm{Mr}$ maintained a normal amplitude until 20 months. The loss of motor units could be preferentially restricted to one type of motor unit. There is indirect evidence from monkey wrist flexors that slow twitch motor units fire predominantly during the M1 interval and fast twitch motor units during the M2-3 (Bawa and Tatton, 1979). If fast twitch motor units atrophy selectively in antigravity muscles in hemiplegics with spasticity as suggested by Edstrom (1970) it might be possible to obtain artificially increased $\mathrm{Ml}$ interval/Mr ratios. In this study no correlation between the $\mathrm{Ml}$ interval/Mr ratio and the duration of lesion could be determined and serial testing demonstrated a constant ratio over a two-month period (unpublished observations). Conclusions suggesting a decreased $\mathrm{Mr}$ are unlikely but comparison of absolute $\mathrm{Mr}$ amplitude values, twitch tensions and single unit recordings between the affected and the unaffected limb will be necessary to unambiguously examine the possible contribution of atrophy.

The hemiplegic subjects who had an increased $\mathrm{Ml}$ interval were the same subjects who had an absence or decrease of 
EMG activity during the normal M2-3 interval. There has been no general agreement as to the functional role of the long latency response (see Wiesendanger and Miles, 1982 for a recent review). However, the evidence that the motor cortex contributes to the $\mathrm{M} 2$ activity for distal upper limb muscles in primates is compelling. Lesions in area 4 in the motor cortex result in reduced $\mathrm{M} 2$ activity in the contralateral limb in the squirrel monkey independent of background activity (Lenz et al., 1983b). In addition, Cheney and Fetz (1984) using spike triggered averaging techniques have been able to show motor cortical neurons in area 4 responding to wrist displacements with conduction times appropriate to contribute to the $\mathbf{M}_{2}$ segment. Accepting the evidence for homologous responses in monkey and human wrist muscles (Bawa and Tatton, 1979; Lenz et al., 1983a; Tatton et al., 1983), similar conclusions appear appropriate for a motor cortical contribution to the long latency activity for the wrist flexor musculature in humans. The fact that $\mathrm{M} 2$ interval activity which is prominent in the forearm flexors in monkeys is decreased or absent after middle cerebral artery occlusion (Lenz et al., 1984) also illustrates that vascularly induced cerebral lesions can disrupt long latency EMG activity. Therefore, the decreased M2-3 interval activity is likely, at least in part, to result from interruption of a transcortical pathway.

This abnormal segmental response pattern for the wrist flexors in hemiplegia is different than the segmental pattern of EMG activity in Parkinson's disease where the M2-3 is increased, or dystonia musculorum deformans where the longlatency activity is prolonged (Tatton et al., 1984b) or in Huntington's chorea where the short latency activity is comparable to normals but the long latency segment is selectively decreased or absent (Noth et al., 1983). Precise identification of the anatomical location and extent of the vascular lesions with nuclear magnetic resonance techniques or computerized tomography might help clarify why two thirds of the hemiplegic subjects showed this stereotyped response while one third had varying segmental response patterns. Clearly knowledge of the site of the lesion is critical to draw further conclusions about the role of transcortical pathways.

In conclusion, this study demonstrates that in hemiplegics with non-homogeneous clinical profiles the abnormal segmental EMG activity in response to imposed displacements was highly reproducible in two thirds of the subjects tested. The mechanisms responsible for the alterations seen in hemiplegia may be multifactoral. Clearly central excitability is altered as increased MI segments are elicited at spontaneously low background EMG levels. This increased central excitability is most likely due to a disruption of polysynaptic internuncial influences on alpha motoneurons. Activity normally mediated by a transcortical pathway could be interrupted by the vascular lesion. With the abnormally increased $\mathrm{M} 1$ segment, the motoneurons influenced by these transcortical projections, that normally fire during the M2-3 interval may not be able to generate activity due to relative refractoriness. To provide further clarification it is essential to do single unit recordings with tension profiles at different background levels to clarify the different contributions of single motor units to the MI interval and Md in hemiplegia.

\section{ACKNOWLEDGEMENTS}

The research was supported by the Physicians' Services Incorporated Foundation, the Jackman Neuroscience Fund and the Medical Research
Council of Canada Grant MT5218. The authors are grateful to W. Bedingham for development of the data analysis system, R. Andrews and M. LaCaria for computer and technical assistance and to Dr. W. Franks for participation in the development of the laboratory.

\section{REFERENCES}

Bawa Pand Tatton WG (1979) Motor unit responses in muscles stretched by imposed displacements of the monkey wrist. Exp. Brain Res. 37: 417-438.

Bedingham W and Tatton WG (1984) Dependence of EMG responses evoked by imposed wrist displacements on pre-existing activity in the stretched muscles. Can. J. Neurol. Sci. (this issue).

Berardelli A, Sabra AF, Hallet M, Berenberg W and Simon SR (1983) Stretch reflex of triceps surae in patients with upper motor neurone syndromes. J. Neurol. Neurosurg. Psychiat. 46: 54-60.

Burke D, Gandevia SC and McKeon B (1983) The afferent volleys response for spinal proprioceptive reflexes in man. J. Physiol. 339: 535-559.

Burke D, Gandevia SC, McKeon B (1984) Monosynaptic and ogliosynaptic contributions to the human ankle jerk and $\mathrm{H}$ reflex. J. Physiol. In press.

Chan CWY, Melvill Jones G, Kearney RE and Watt DGD (1979) The "late" electromyographic response to limb displacement in man. Electroencephalogr. Clin. Neurophysiol. 46: 173-181.

Cheney PD and Fetz EE (1984) Primate cortical motoneuronal cells contribute to long latency stretch reflexes. J. Physiol. In Press.

Edstrom L (1970) Selective changes in the sizes of red and white muscle fibres in upper motor lesions and Parkinsonianism. J. Neurol. Sci. 11: $537-550$.

Garcia-Mullin R and Mayer RF (1972) $\mathrm{H}$ reflexes in acute and chronic hemiplegia. Brain 95: 559-572.

Granit R (1955) Receptors and Sensory Perception. Yale University Press, New Haven, pp. 273-275.

Hagbarth KE, Wallin G and Lofstedt L (1973) Muscle spindle responses to stretch in normal and spastic subjects. Scand. J. Rehab. Med. 5: 156-159.

Lee RG and Tatton WG (1975) Motor responses to sudden limb displacements in primates with specific CNS lesions and in human patients with motor system disorders. Can. J. Neurol. Sci. 2: 285-292.

Lee RG and Tatton WG (1978) Long loop reflexes in humans: Clinical application. In Cerebral Motor Control in Man: Long Loop Mechanisms. Desmedt, J.E. ed. Prog. Clin. Neurophysiol. Karger, Basel, 4: 229-245.

Lee RG and Tatton WG (1982) Long latency reflexes to imposed displacements of human wrist: Dependence on duration of movement. Exp. Brain Res. 45: 207-216.

Lee RG, Murphy JT and Tatton WG (1983) Long-latency myotatic reflexes in man: Mechanisms, functional significance and changes in patients with Parkinson's disease or hemiplegia. In: Motor Control Mechanisms in Health and Disease. Desmedt, J.E. ed. Raven Press. New York. Adv. Neurol. 39: 489-508.

Lenz FA, Tatton WG and Tasker RR (1983a) Electromyographic response to displacement of different forelimb joints in the squirrel monkey. J. Neurosci. 3: 783-794.

Lenz FA, Tatton WG and Tasker RR (1983b) The effect of cortical lesions on the electromyographic response to joint displacement in the squirrel monkey forelimb. J. Neurosci. 3: 795-805.

Lenz FA, Tasker RR, Tatton WG and Halliday W (1984) Long-latency reflex activity in a primate MCA occlusion model of human spasticity. Submitted for publication.

Marsden CD, Merton PA and Morton HB (1977a) The effect of posterior column lesions on servo responses from the human long thumb flexor. Brain 100: 185-200.

Marsden CD, Merton PA, Morton HB and Adam J (1977b) The effect of lesions of sensorimotor cortex and the capsular pathways on servo responses from the human long thumb flexor. Brain 100: 503-526.

McComas AJ, Sica REP, Upton ARM and Aguilera N (1973) Functional changes in motoneurons of hemiparetic patients. J. Neurol. Neurosurg. Psychiat. 36: 183-193.

Noth J, Friedmann HH, Podoll K and Lange HW (1983) Absence of long latency reflexes to imposed finger displacements in patients with Huntington`s disease. Neurosci. Letters, 35: 97-100. 
Somerville J and Ashby P(1978) Hemiplegic spasticity: Neurophysiologic studies. Arch. Phys. Med. Rehabil. 59: 592-596.

Szumski AJ, Burg D, Struppler A and Velho F (1974) Activity of muscle spindles during muscle twitch and clonus in normal and spastic human subjects. Electroencephalogr. Clin. Neurophysiol. 37: 589-597.

Tanaka R (1983) Reciprocal la inhibitory pathway in normal man and in patients with motor disorders. In: Motor Control Mechanisms in Health and Disease Desmedt. J.E. ed. Raven Press, New York, Adv. Neurol. 39: 433-441.

Tatton W and Bedingham W (1981) Characteristic long-latency reflex abnormalities in dystonia and rigidity. Can. Congress Neurol. Sci. 12: 138 .

Tatton WG, North AGE, Bruce IC and Bedingham W (1983) Electromyographic and motor cortical responses to imposed displacements of the cat elbow: Disparities and homologies with those of the primate wrist. J. Neurosci. 3: 1807-1817.
Tatton WG, Bedingham W, Verrier MC, Bruce IC and Blair RDG (1984a) Abnormalities of mechanoreceptor-evoked electromyographic activity in central motor disorders. Thieme publishers, Stutgart, Germany. In press.

Tatton WG, Bedingham W, Verrier MC and Blair RDG (1984b) Characteristic alterations in the response to imposed wrist displacements in Parkinsonian rigidity and dystonia musculorum deformans. Can. J. Neurosci. (this issue)

Wiesendanger M and Miles TS (1982) Ascending pathway to lowthreshold muscle afferents to the cerebral cortex and its possible role in motor control. Physiological Reviews, 62: 4, 1234-1270.

Zander-Olsen P and Diamantopoulos E (1967) Excitability of spinal motor neurones in normal subjects and patients with spasticity Parkinsonian rigidity and cerebellar hypotonia. J. Neurol. Neurosurg. Psychiat. 30: 325-331. 